\title{
Cribriform Adenocarcinoma of Minor Salivary Gland
}

National Cancer Institute

\section{Source}

National Cancer Institute. Cribriform Adenocarcinoma of Minor Salivary Gland. NCI

Thesaurus. Code C160974.

A minor salivary gland adenocarcinoma characterized by a cribriform pattern. It often metastasizes to the neck lymph nodes. 